\title{
Color design in the outdoor sports leisure clothing
}

\author{
Funan $\mathrm{Cai}^{1, \mathrm{a}}$ \\ ${ }^{1}$ Jiangxi Institute of Fashion Technology, Jiangxi, Nanchang, 330201 \\ a28181357@qq.com
}

Keywords: Outdoor sports; Casual clothes; Color design

\begin{abstract}
Outdoor sports tourism and sports together in a new sports leisure way. In recent years, outdoor sports apparel industry is booming up stage of development, more and more fashion designers into sports leisure clothing design. This paper focuses on the color design of outdoor sports leisure clothing must explore, expounds the classification and color characteristics of outdoor sports leisure clothing, finally analyzes the use and practice of outdoor sports clothing color.
\end{abstract}

\section{Introduction}

At home, outdoor sports development is still in its early development stage, its development space is larger and the way of the future is also twists and turns tough, let us go to from various aspects constantly to perfect and innovation. Outdoor sports clothing design should not only consider the functionality and activity, also added more fashion elements in design. In the aspect of color design and collocation should not only consider the color of the bright eye-catching, the fashion colour should also be combined with the quarter and popular trend to carry on the design.

\section{The concept and classification of outdoor sportswear}

Outdoor sportswear and sports is equipped with a certain difference, it has a clear functional and technical content, clothing joined the high-tech synthetic materials, inside structure takes advantage of the human body engineering, physics, biology, make body stretch freely in the leisure sports. Sportswear, on the other hand, the design feels strong, on the basis of leisure, combines the motion cueing, vitality and fashion. Sportswear designed mainly for sports clothing, professional and oneness, and outdoor sports casual wear in addition to the outdoor sports wear is given priority to, also can be in the usual shopping and leisure wear, wider application scope. Outdoor sports casual wear on price is much higher than that of general sports clothes and casual wear, in addition to the outdoor brands have value and technology content, outdoor sportswear fabrics, materials and technology represents the most advanced, cutting-edge level of textile.

Outdoor sportswear according to different classification according to their classification, the classification result is different also. Mainly according to the physiological load of exercise, sports environment, fashion, sports category, wearing system to classification, specific classification as shown in table 1:

Table 1 The classification of the outdoor sportswear

\begin{tabular}{|c|c|c|c|}
\hline Exercise intensity & $\begin{array}{c}\text { Sports } \\
\text { environment }\end{array}$ & Sports categories & In system \\
\hline Light intensity & land & The limit movement & The innermost \\
\hline General exercise intensity & waters & The limit movement & The middle layer \\
\hline High intensity & airspace & Leisure sports & The outermost layer \\
\hline
\end{tabular}

\section{The characteristics of outdoor sports casual wear}

Outdoor sports casual wear has a variety of functions can cope with the outdoor environment of complex and changeable situation, for example, windproof, waterproof, waterproof and breathable, 
moisture permeability, abrasion resistance, etc. According to the function different, your clothes are divided into three layers: the innermost, basic layer, used for close-fitting wear, used for keeping warm, sweat, and antibacterial. Clothing lining once the accumulation of too much sweat, can make people easy to catch a cold, sometimes may cause frostbite. The middle layer, has the thermal insulation, windproof, breathable, generally used in the cold region. Filling down or chemical fiber cotton used for heat preservation. Coat layer functionality is the most important functional parts of the whole clothes have windproof, waterproof, breathable, wear-resisting, resistance to ultraviolet radiation. External fabric demand is higher, although to be waterproof, but must be well ventilated, a layer of gelatin film by joining in the inner fabric, the fabric layer with different morphology and particle size of the water to breathe freely. Under the interface of thin film, thin film on the surface of the pore diameter are between water molecules and molecules of steam, steam molecules can be spread through, while the water molecules were blocked, enter within the material, so as to achieve the effect of waterproof and breathable.

\section{The characteristics of outdoor sports leisure clothing color}

Outdoor sportswear design not only combines the basic function of sports clothes and casual style design characteristics, also in view of the outdoor environment, to design and color is tie-in. Outdoor sports leisure clothing, this paper discuss respectively from the color of the beautiful sex, functional and collocation method is discussed.

The color of the beautiful sex. Along with society's progress and the abundance of material life, human physical labor intensity is abate, many workers don't have to, directly or indirectly, in a natural environment to work and activities, and occasionally walk into nature became people relax themselves instead of a way of entertainment. Under the social life of the rich people spiritual pursuit, also its aesthetic appeal also pay more attention to. For outdoor sportswear, in addition to its functional, also more and more attention to its beauty and fashion. People in the outdoor exercise will focus on the outer clothing of self and others, so there is always hope to show in front of the people have the best state to others.

Each color has a different meaning and function of color can attract eyeball, rendering situation, expressing opinions, build brilliant elegant atmosphere, different tonal harmonic will also bring different aesthetic intent. Relatively before coloring, outdoor sportswear, colour is applied more and more bold and progressive, keep up with fashion trends. Fashion elements are increasingly used in outdoor sports leisure clothing, outdoor sportswear changed the monotonous traditional sportswear design, more than ever on colour choice bold fashion, large area USES bright, cheerful colour ornament collocation. Especially the women's clothing, pink, dark blue, fruit-green, fruit such as light yellow colour and forest on senior ash, use of color in the color of movement and rhythm makes the movement young fashion women more attractive. More halfback some designers added specular bright color and metal color, give a person with sense of science and technology and the modern.

The functional sex of the color. The functional sex of the outdoor sports leisure clothing design conditions and factors that should be considered more complex, want to consider comprehensive, coordinate the relationship between the elements. The design process must be observed from the human body, and then to the structure of the human body, form with the surrounding environment and other aspects. And the focus of the clothing and the core main consideration of different human body shape, motion mechanism, physiological and psychological factors, make the garment structure match the human body structure and form. In the clothing version of type design, often through segmentation, fold, the province a finesse, draping technique make the garment cutting more accord with human body engineering principle.

Outdoor sports leisure clothing color cautionary, trademark, in the process of rapid movement, the color of clothing can make peers and rivals easily found and avoid targets. For example, in the process of skiing, natural environment is easy to keep out the line of sight, the bright eye-catching colors can help are outdoors to see each other to avoid collision accident. Different circumstances of different colours visible degree is different also, at this time the color will play a warning role. 
Outdoor sports with a certain risk, in the event of an accident, only to peers or external to seek relief, in the process of rescue, colorful clothing has become an important object looking for targets. So color choice in general is given priority to with bright color, color choices tend to be high purity, tall lightness, these color with tall lightness commonly the is the best ideal colour such as red, yellow, and blue. These colour when outdoor activities easy to distinguish with natural vegetation, forest color, one thousand people lost or left behind easy to identify.

Colour aesthetic. Human through long-term experience in aesthetic creation and appreciation, summarizes some aesthetic principles: on the one hand, the combination of the color relations is mutual harmonious and unified, on the other hand the collocation between elements well are independent of each other. Can also compared the collocation of color imaging music melody as organized, regular change, can the collocation of phase type, from shallow to deep, from light to dark, or multiple collocation, the colour change multiple attributes, but at the same time.

The design of outdoor sports leisure clothing fabrics no daily variety, restricted by a certain. But its also follow the principle of color and beautiful color, suitable for combination of colours make the garment look more fashionable and beautiful. Mainly for with and without color color collocation, the collocation of the specific methods are divided into the collocation of color and without color, color collocation fastens with color, have a color contrast collocation, the collocation of color. But practical application, the main three attributes or see color change and the patch size, shape and position distribution, constantly adjusted to get the best visual effect and the aesthetic demand.

\section{Practice of outdoor sports leisure clothing color}

Design inspiration and ideas. By inspiration picture thought of wearing a bold, movement of the outdoor sports, outdoor sports dazzling colour in monotonous quiet snowy beats, seem to see the life also in the beating, that moment let a person very excited and excited, just like hope in the lost. Glowing lime green and fresh quietly elegant yellow spots, with fashion and postmodern sensation. Two colors bright and eye-catching, make public youth and vigor, the ornament of the gray down the too bright and beautiful with unabashed individuality, and make the overall tone is more stable, harmonious, as shown in figure 1.

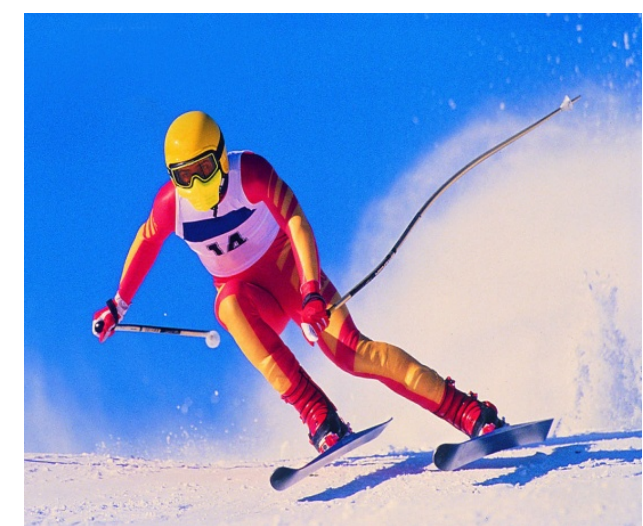

Fig.1 Inspiration images

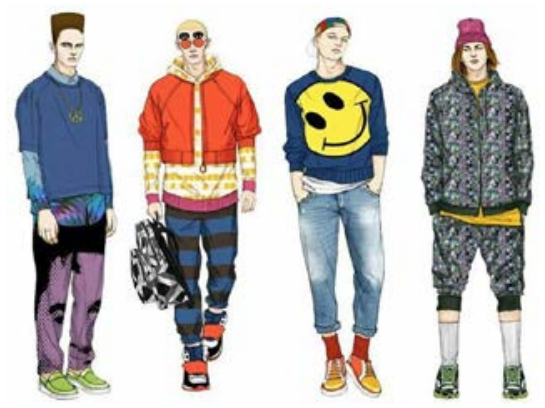

Fig. 2 Design renderings

The characteristics of the design. In addition to the vigor of young people like sports and outdoor exploration, and now work in the city of men working pressure at ordinary times, all day in the gray iron cement construction, live and work in the multiple pressures, they are more looking for release the habitat of soul. The design of garment design mainly for outdoor sports clothing for the design of extension of class, refer to the outdoor sports of bright colors, main color for the lime green and yellow, then to try to adorn with gray and match. Is given priority to with segmentation and stitching design, clothing structure design highlights for metallic zippers and snaps, there are both practical and strong visual and decorative effect, as shown in figure 2.

Colour and design analysis. Light yellow bright, light, soft and opening up, with the feeling of wisdom, yellow coat with raglan sleeve convenient human movement, loose high-necked coat, not 
only to keep warm in style, and with baggy pants collocation is full of lively, youth and vigor of recreational feeling. Lime green can give a person the feeling of cool and comfortable, it has a yellowish green fresh with the youth breath and tender feeling. Light green long coat and yellow phase, intermediate in embedded with a grey fabrics, integral feeling strong and harmonious. Collar is mainly for the collar, with metal snap button and zipper, among them two reference outdoor sportswear design has brought the cap and turtleneck cap, with recreational and fashionable feeling.

\section{Conclusion}

With the development of economy and society, outdoor sports will also entered the stage of rapid development in our country, and the current outdoor sports casual wear industry in China has been growing more slowly, brand competitiveness, product quality and design ability relative to foreign goods are also far, there is a long progress and development space. As an outdoor enthusiasts, hope that our country outdoors leisure brand to make their own achievements, and more people are wearing their own brand of outdoor sports casual wear, can see it on the big stage, puts glorious greatly. At the same time as a fashion designer, more hope we can design the fashionable, smart, functional and environmental protection of outdoor sports leisure clothing.

\section{Reference}

[1] Gaoming Jiang. Lizhe Zhang. Knitted sports leisure fabric development [J] textile herald, 2009 (9).

[2] Caihong Chen. Analyze the factors influencing the sportswear design and development prospect are $[\mathrm{J}]$ the international textile herald, 2007 (04).

[3] Chunhua Xu. Outdoor sports clothing color research [D] donghua university, 2012 (12). 